\title{
The Strength Characters of C/C Composite Material with Opening Hole and Typical Application
}

\author{
Zhiyong Tan, Changwan Min, Xuyun Zhan, Weili Dong \\ Science and Tehnology on Space Physics Laboratory, Beijing, China \\ Email: tanzhy_01@163.com
}

How to cite this paper: Tan, Z.Y., Min, C.W., Zhan, X.Y. and Dong, W.L. (2017) The Strength Characters of C/C Composite Material with Opening Hole and Typical Application. Journal of Materials Science and Chemical Engineering, 5, 61-68. http://dx.doi.org/10.4236/msce.2017.51009

Received: September 19, 2016

Accepted: January 1, 2017

Published: January 4, 2017

\begin{abstract}
Research on the opening hole and connecting problem of C/C composite material was conducted. The strength characteristics of plate with opening hole were tested and the applicability of strength criteria focused on particular point was analyzed. Conclusion is obtained that obviously conservative to evaluate open hole and joint strength by hole-edge stress. Based on these, high and normal temperature strength test of typical circular shaft was completed, proving that comprehensive joint performance can be significantly improved by appropriately optimized design.
\end{abstract}

\section{Keywords}

Composite Material, Opening's Characteristics, Joint Strength

\section{Introduction}

As a new type of ultra-high temperature composite material, $\mathrm{C} / \mathrm{C}$ is one of the important alternatives to primary load bearing thermal protection structure in newly aircraft. In order to meet the requirement of disassembly of parts, in consideration of the limitation of using adhesives in high temperature environment, mechanical joint is an irreplaceable choice.

The basis of mechanical joint is the thorough understanding of the mechanical properties of structure with structural opening and reinforcement. In the system of advanced composite materials, numerous studies have been done on the opening and joint properties of resin matrix composite material. Xie Mingjiu [1] used industrial method to carry out systematic discussion and draw conclusion. Wang Fusheng [2] did research into the effect of the shape of opening and fit clearance on properties. Song Zuoyu [3] studied the joint characteristics of 
different opening forms of resin matrix material. These studies indicate that resin matrix composite material has been maturely applied to primary load bearing structure in aviation field. However, $\mathrm{C} / \mathrm{C}$ composite material is very much different from resin matrix material in mechanical properties and representation. The basic mechanical properties and performance of $\mathrm{C} / \mathrm{C}$ material were comprehensively introduced. However, in-depth researches on the $\mathrm{C} / \mathrm{C}$ material's opening and joint are rare in research reports. Relevant experiment shows [4] 4that the complicated three-dimensional stress and strain distribution at the opening, influential factors on mechanical joint (type of joint, environmental temperature, material's thermal suitability, geometrical dimension of joint, type and dimension of fasteners, influence of pretension force, dimension error between fastener and connecting hole, etc.) can't copy the laws and conclusions of resin matrix material.

To explore problems of $\mathrm{C} / \mathrm{C}$ thermal protection structure's need for mechanical joint, structural design and loading features, this thesis carried out research on typical experimental sample's mechanical properties and joint problems, including the regularity of $\mathrm{C} / \mathrm{C}$ material's opening hole strength and extruding strength characteristics. After testing plate with opening holes about its characteristics at normal temperature, the experiment drew the conclusion that material's tensile strength is not sensitive to opening hole, and analyzed the applicability of strength criteria focused on particular point based on the results of experiment. On the basis of theoretical analysis, typical circular shaft's way of joint in high-temperature environment was analyzed and improved, validated by strength experiment in high and normal temperature. So it indicates that reasonably optimized design can improve the performance of composite joint.

\section{Test the Strength Characteristics of C/C Plate with Opening Holes and Analyze the Applicability of Point Strength Criteria}

The experimental sample for tension and extrusion of $\mathrm{C} / \mathrm{C}$ open hole uses stack-switched carbon cloth. The carbon cloth is T300-3K double damask; stacking sequence is $0^{\circ} / 90^{\circ} / 45^{\circ} / 0^{\circ} / 90^{\circ} /-45^{\circ}$; sutures are (T300 - 3K + T300 $1 \mathrm{~K}) \times 2$; suture spacing is $4 \mathrm{~mm}$; fiber content of the plate is about $45 \%-48 \%$. The experimental sample's width is $20 \mathrm{~mm}$.

Strength characteristics were obtained after doing tension experiment toward plate with opening holes. Diameters of opening holes are $2 \mathrm{~mm}, 4 \mathrm{~mm}, 6 \mathrm{~mm}$ and $8 \mathrm{~mm}$ respectively. In experiment, strain gages were pasted in parallel on each side of opening hole. The material's tensile strength with opening hole obtained from the experiment was implemented nominal strength formula, that is:

$$
\sigma_{\text {bnom }}=\frac{P_{\max }}{A_{0}}
$$

In the formula, $\sigma_{\text {bnom }}$ is sample's nominal tensile strength, $P_{\max }$ is the maximum failure load, $A_{0}$ is nominal sectional area (including sectional area of hole) The changes of sample's nominal strength with different apertures and 
typical failure were displayed in Figure 1. The nominal strength when opening hole diameter is 0 , is the average strength value of standard tensile sample. It's obvious that when the diameter of opening is smaller than $4 \mathrm{~mm}$, the sample's strength wasn't decreased evidently, which indicted that tensile strength is not sensitive to round opening hole.

Figure 2 presents the stress-strain test results of 2 samples without opening, and a single sample with a $6 \mathrm{~mm}$ opening at different locations of the surface with opening. Through analysis, the conclusion can be drawn that samples without opening are consistent. Since C/C's tensile properties are primarily controlled by fiber, so it demonstrates obvious linear and brittle characteristics, and failure strain is about $1600 \mu \varepsilon$. As to the sample with opening, strain of the location far away from opening is somewhat lower than failure strain of the sample without opening. There is stress and strain concentration around opening, which is also the location where failure first occurs. Comparing Figure 1 with Figure 2, it's obviously conservative to evaluate open hole and joint strength by hole-edge stress. The conservative quantity of the sample with $6 \mathrm{~mm}$ opening is 1.9 times.

Point strength criteria can be adopted to evaluate the strength in condition of stress concentration, that is, using special stress in some local area to evaluate the failure load of sample with opening under tensile/compressive load. It is a
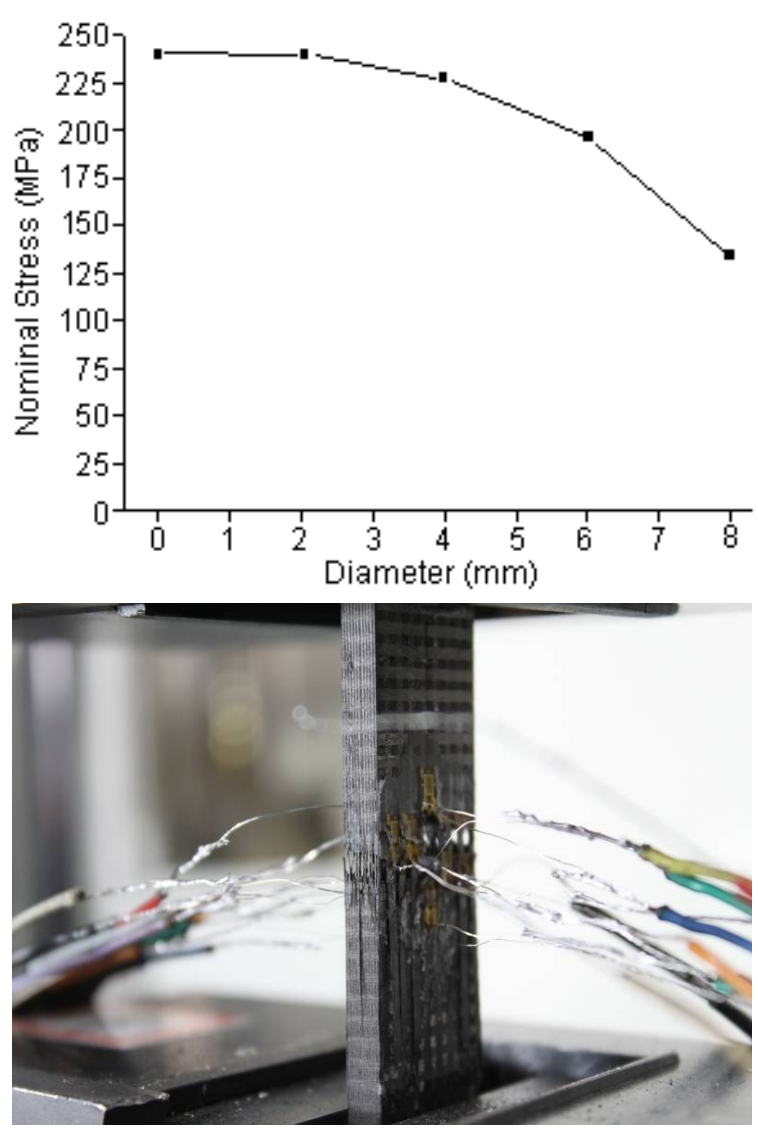

Figure 1. Nominal strength change law for openings of different diameters and typical failure of sample. 

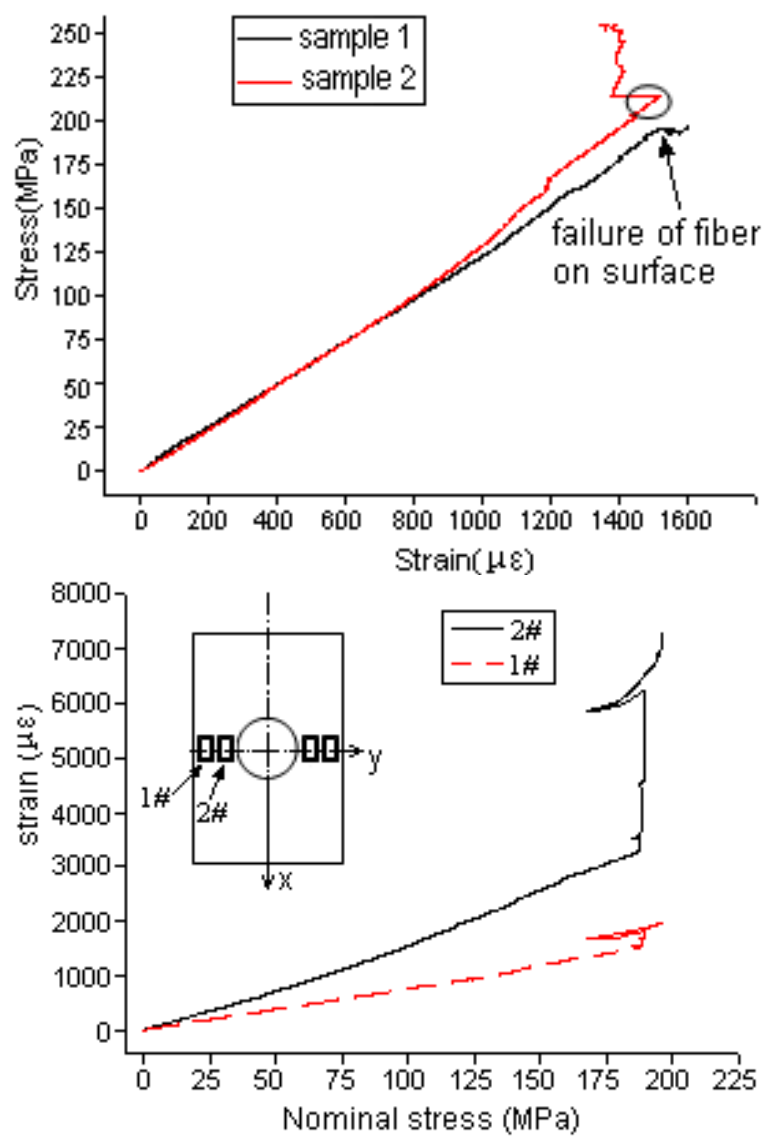

Figure 2. Typical stress-strain curves of samples without opening and sample with $6 \mathrm{~mm}$ opening.

simple method based on two parameters which are $\sigma_{b 0}$, the strength of plate without opening hole, and $d_{0}$, the characteristic dimension of the hole. Kogo Y [5] used this method to forecast well the composite laminated plate specimen with two-dimensional $\mathrm{C} / \mathrm{C}$ notch.

K. Sabeel Ahmed [6] gave the theoretical calculation formula of strength criteria focused on particular point, wherein $d_{0}$, the characteristic dimension, is defined as the distance between the point at which the stress on the plate reaches the tensile/compressive strength without opening hole and the hole edge when the opening hole failure occurs, so:

$$
\sigma_{b}\left(0, R+d_{0}\right)=\sigma_{b 0}
$$

When formula (2) is met, failure occurs on the plate with opening hole. Stress analysis is conducted under linear condition for the semi-infinite plate with opening hole, obtaining the ratio of the strength of plate with opening hole to that of plate without opening hole:

$$
\frac{\sigma_{b}}{\sigma_{b 0}}=\frac{2}{\left[2+\beta^{2}+3 \beta^{4}-\left(K_{T}^{\infty}-3\right)\left(5 \beta^{6}-7 \beta^{8}\right)\right]}
$$

where: $\beta=R /\left(R+d_{0}\right), R$ is the radius of the central opening hole, $K_{T}^{\infty}$ is 
the stress concentration factor, which can be calculated by the formula below:

$$
K_{T}^{\infty}=1+\sqrt{2\left(\sqrt{E_{x} / E_{y}}-\mu_{x y}+E_{x} /\left(2 G_{x y}\right)\right)}
$$

where: $E_{x}, E_{y}$ are Young's modulus in two directions, $G_{x y}$ is in-plane shearing modulus, and $\mu_{x y}$ is Poisson's ratio.

As a geometric parameter relevant to the failure region, a specific physical interpretation has not yet been given for $d_{0}$, which generally can be obtained by finite element calculation and test. Considering the stress distribution obtained by finite element method has some human assumption factors, in this paper, the characteristic dimension is obtained from the measured strain data of a test specimen with $6 \mathrm{~mm}$ opening hole under tensile failure load, which is $4.0 \mathrm{~mm}$. According to tensile and in-plane shear test specimen without opening hole, obtain that $E_{x}=E_{y}=85 \mathrm{GPa}, \mu_{x y}=0.035, G_{x y}=20 \mathrm{GPa}$, substitute these data into the above formulas, obtain the ratio of the strength of plate with opening hole to that of plate without opening hole, which is 0.88 ; while the ratio measured through the test is 0.84 . Thus, this shows that the point strength criterion, as a simple but effective forecasting method, has a good applicability in the test. The reason why the theoretical result is slightly higher is that the directly used characteristic dimension measured from the test is slightly larger, which should include the influence of test error, dispersion of subsample and distinguishing method of singular data near the failure load. Correct the theoretical result, then a relatively identical and safe result can be obtained when $d_{0} \approx R$. The characteristic dimension is relevant to several factors such as material, opening hole size, edge condition, etc., so generally, the conclusion is only applicable to specified conditions. To different practical situations, it should be determined through a large number of tests.

\section{Optimized Application of Joint Performance of C/C Typical Circular Shaft}

The bearing capacity of circular shaft is the key of thermal structure such as rudder and flaperon, etc., and the weak link of the strength of circular shaft is generally relevant to the position of opening hole and the bolted joint. The stress state near the position of opening hole is complicated, which needs to consider many factors. To ensure enough loading transfer capacity, the circular shaft is usually adapted as bolted joint with double-column and even multi-column opening hole. So, it is necessary to analyze the effect of extruding and tensile load to each hole, and to ensure the bearing rationality of the hole in each column. Establish the relationship of ratio between the extruding and tensile stress of the loaded hole of shear bolted joint sample, which can reflect the combined action effect of the two. The formula is determined through below:

$$
K_{j y} \sigma_{j y}+K_{t c} \sigma_{b}=\sigma_{b 0}
$$

where: $\sigma_{b 0}$ is the tensile strength of material without opening hole, $\sigma_{j y}$ is the extrusion stress of loaded hole, $\sigma_{b}$ is the net section tensile stress caused by by- 
pass load. $K_{j y}$ is the extrusion stress concentration reduction factor of hole loaded, and $K_{t c}$ is the tensile stress concentration reduction factor of opening hole. According to the formula in related article [7] [8] and using the test specimen with $8 \mathrm{~mm}$ opening hole in this paper, the sketch map of failure envelope for a single opening hole under the combined action of tension and extrusion is shown in the figure below. Extrusion failure occurs on the joint structure in the grey $\mathrm{OAB}$ area, and tensile failure occurs on the joint structure in the white $\mathrm{OBC}$ area. This is used as the foundation of optimized application of $\mathrm{C} / \mathrm{C}$ typical circular shaft, which is under flexural-torsional combined load.

By Figure 3, tensile failure should be more attention for this sort of opening hole. For the actual circular shaft, factors need to be considered when structural design include shape of opening hole, size dimension, interval and stiffness of connecting bolt, moment of pre-tension and interval, etc. It is necessary not only to achieve the optimization under normal temperature, but also to consider the possible influence of high-temperature thermal expansion and additional heat stress. Under normal conditions, the need for large diameter of opening hole of circular shaft and for proper stiffness of bolt is somewhat contradictory. By notching or hollowing, the stiffness of metal bolt with large diameter can be reduced, so as to achieve the stiffness matching of multi-column bolt. Changing the shape of opening hole moderately can reduce stress concentration for special load condition, which can be achieved through bolt bushing in the structural design.

Figure 4 gives the situations of opening hole joint and high and normal temperature test of a C/C typical circular shaft. 3 columns of through holes are opened at each end of the circular shaft, which are connected by metal bolts. Choose the above factors as the variables to make numerical analysis and optimized design. Under initial design condition, the ratio of load bearing of column 1,2 and 3 bolt (i.e. the extrusion load of opening hole) is about 65:25:10, while, after optimization, hole diameter:hole interval $\approx 4$, and the ratio of load bearing

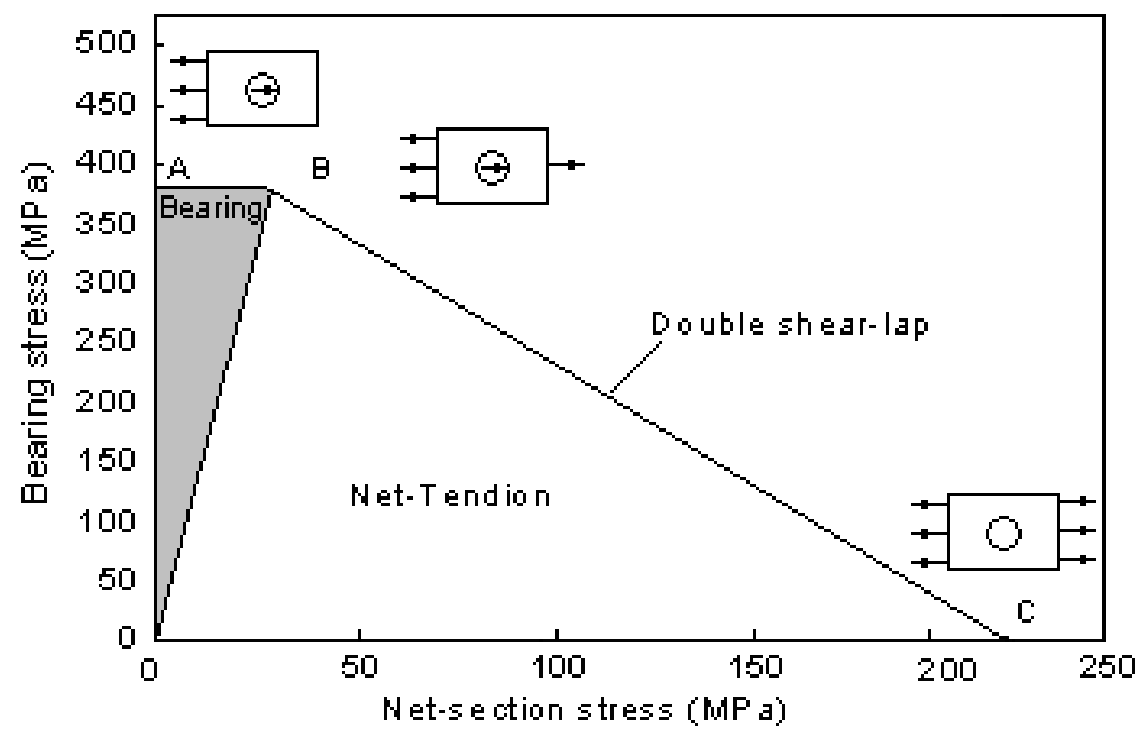

Figure 3. Failure envelope of double shear opening hole joint of $\mathrm{C} / \mathrm{C}$ test specimen. 


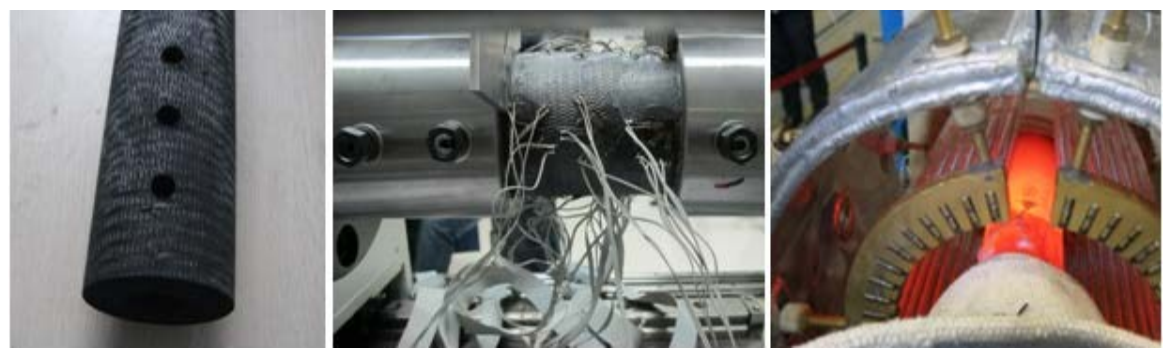

Figure 4. Opening hole joint and high and normal temperature bearing test of typical circular shaft.

of these three columns of bolt is 45:35:20. Each opening hole tends to bear a uniform load. Additionally, the distribution of the extrusion load and the bypass load is more reasonable, and it also considers the influence of high-temperature heating. The test result verifies the effect of the optimized design, and that the circular shaft failure does not occur at the position of the opening hole.

\section{Conclusions}

By summarizing the typical opening hole test of $\mathrm{C} / \mathrm{C}$ composite material, we can know that the rule of strength of opening hole obtained from the study is an important basis of connection design and analysis of bolt-like machinery. And the specific stress concentration sensitivity coefficient and the characteristic length by strength criteria focused on particular point are obtained in this paper. However, there are a lot of factors involved in connection of opening hole of the actual structure, so it is necessary to make a reasonable optimization. Thus, the typical circular shaft is applied in this paper.

With respect to the relevant follow-up work, study on mechanical properties of opening hole of a typical test specimen under high temperature will be conducted, to discuss the coupling property and heat matching characteristic of heat stress and external load stress. Moreover, the testing technique and the oxidation resistance technique under high temperature are both difficulties that need to be solved.

\section{Acknowledgements}

The research work is supported by the National Science Foundation of China (11572086).

\section{References}

[1] Xie, M.J. (2011) Connection of Composite Materials. Shanghai Jiaotong University Press, Shanghai.

[2] Wang, F.S., Liu, Y. and Yue, Z.F. (2010) Analysis of the Influence Factors on Mechanical Properties of Single-Bolted Composite Laminates. Journal of Materials Science and Engineering, 28, 58-61

[3] Song, Z.Y., Wang, X.C., Cao, Z.H., Qiu, Q.Y. and Kou, Z.J. (2009) Mechanical Properties of Connection of the Carbon Fiber/Polyimide Resin Matrix Composite Material Opening Hole Piece. Aeronautical Manufacturing Technology, S1, 139-144. 
[4] Wang, P.Y., Zhu, Z.T., Wang, F.S. and Yue, Z.F. (2008) Dispersibility and Reliability Analysis of Composite Laminates Bolted Joint. Chinese Quarterly of Mechanics, 29, 573-577.

[5] Kogo, Y. and Hatta, H. (1998) Effect of Stress Concentration on Tensile Fracture Behavior of C-C Composites. Journal of Composite Materials, 32, 1273-1294. https://doi.org/10.1177/002199839803201302

[6] Sabeel Ahmed, K., Vijayarangan, S. and Naidu, A.C.B. (2007) Elastic Properties, Notched Strength and Fracture Criterion in Untreated Woven Jute-Glass Fabric Reinforced Polyester Hybrid Composites. Materials and Design, 28, 2287-2294. https://doi.org/10.1016/j.matdes.2006.08.002

[7] Hart-Smith, L.J. (2003) Adhesively Bonded Joints for Fibrous Composite Structures. In: Tong, L.Y. and Soutis, C., Eds., Recent Advances in Structural Joints and Repair for Composite Materials, Kluwer Academic Publishers, 173-210. https://doi.org/10.1007/978-94-017-0329-1 6

[8] Hart-Smith, L.J. (1977) Bolted Joints in Graphite/Epoxy Composites. Technical Report NASA CR-144899, National Aeronautics and Space Administration, USA.

Submit or recommend next manuscript to SCIRP and we will provide best service for you:

Accepting pre-submission inquiries through Email, Facebook, LinkedIn, Twitter, etc. A wide selection of journals (inclusive of 9 subjects, more than 200 journals)

Providing 24-hour high-quality service

User-friendly online submission system

Fair and swift peer-review system

Efficient typesetting and proofreading procedure

Display of the result of downloads and visits, as well as the number of cited articles

Maximum dissemination of your research work

Submit your manuscript at: http://papersubmission.scirp.org/

Or contact msce@scirp.org 